2016

\title{
Understanding HIV-related vulnerabilities and stigma among Egyptian youth
}

Nahla G. Abdel-Tawab

Population Council

Doaa Oraby

Population Council

Sally Saher

Sarah Ismail

Follow this and additional works at: https://knowledgecommons.popcouncil.org/ departments_sbsr-pgy

Part of the Demography, Population, and Ecology Commons, Family, Life Course, and Society Commons, and the International Public Health Commons

\section{Recommended Citation}

Abdel-Tawab, Nahla G., Doaa Oraby, Sally Saher, and Sarah Ismail. 2016. "Understanding HIV-related vulnerabilities and stigma among Egyptian youth." Cairo: Population Council. 
UNDERSTANDING HIV-RELATED VULNERABILITIES AND STIGMA AMIONG EGYPTIAN YOUTH 


\section{UNDERSTANDING HIV-RELATED VULNERABILITIES AND STIGMA AMONG EGYPTIAN YOUTH}

March 2016

Nahla Abdel-Tawab Doaa Oraby Sally Saher Sarah Ismail 


\section{POPULATION COUNCIL \\ Ideas. Evidence. Impact.}

The Population Council confronts critical health and development issues-from stopping the spread of HIV to improving reproductive health and ensuring that young people lead full and productive lives. Through biomedical, social science, and public health research in 50 countries, we work with our partners to deliver solutions that lead to more effective policies, programs, and technologies that improve lives around the world. Established in 1952 and headquartered in New York, the Council is a nongovernmental, nonprofit organization governed by an international board of trustees.

Suggested citation: Abdel-Tawab, N., D. Oraby, S. Saher, and S. Ismail. 2016. "Understanding HIV-Related Vulnerabilities and Stigma Among Egyptian Youth," Cairo: Population Council - Egypt Office.

Population Council - Egypt Office

59 Misr-Helwan Agricultural Road, Maadi

PO Box 168, Maadi

Cairo, Egypt - 11431

Tel: 20225255968

Alt Tel. No: (20100)1300-496

Fax: +20225255962

email: info.mena@popcouncil.org

Population Council, Inc.

One Dag Hammarskjold Plaza

New York, NY 10017 USA

popcouncil.org

(c) 2016 The Population Council, Inc.

Any part of this publication may be photocopied without permission from the Population Council provided that copies are distributed without charge and that full source citation is provided. The Population Council would appreciate receiving a copy of any materials in which the text is used. 


\section{Study Team}

\section{Population Council}

Dr. Nahla Abdel-Tawab

Dr. Doaa Oraby

Dr. Sally Saher ${ }^{1}$

Mr. Tarek Alam El-Din

Ms. Gihan Hosny

\section{Consultants:}

Prof. Fattouh El-Shazly

Ms. Sarah Ismail

Ms. Sarah Ghattass

${ }^{1}$ Sally Saher is former program officer at the Population Council - Egypt Office. 


\section{Table of Contents}

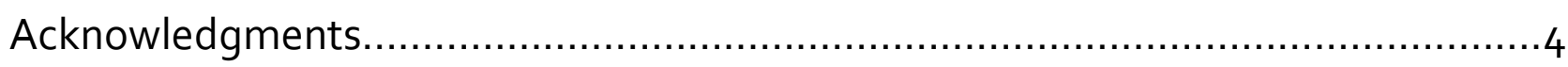

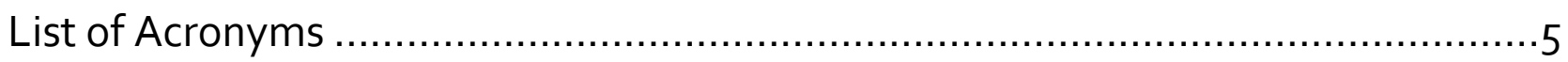

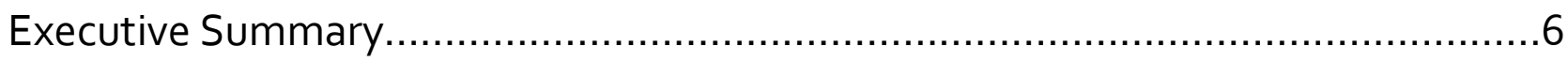

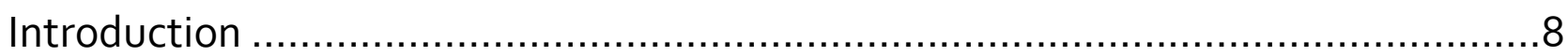

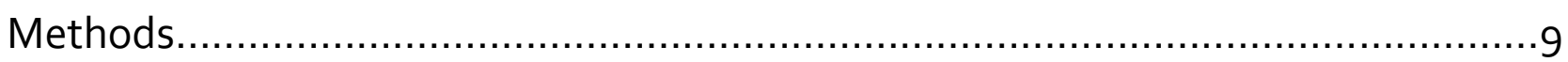

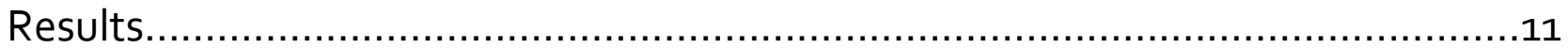

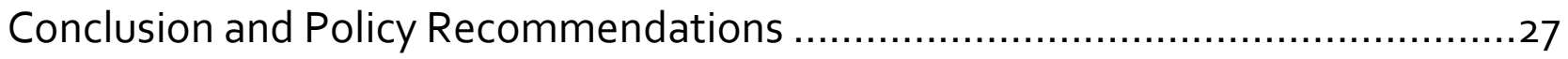

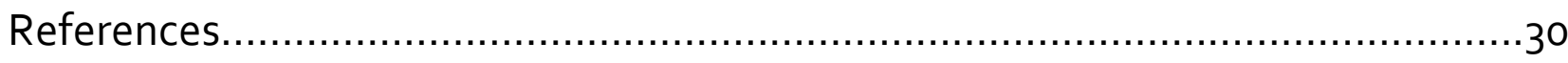




\section{Acknowledgements}

The authors are grateful to all the individuals and organizations that made this study possible. First, we wish to thank our study participants who contributed their time and opinions and shared their personal experiences with us. We also wish to express our sincere gratitude to Dr. Waleed Kamal, National AIDS Program Coordinator for his support of the study and interest in utilization of its results. Assistance from the following NGOs in reaching our study participants is deeply appreciated: Al Shehab, Anba Moussa, Befrienders, Friends of Life, Egyptian Family Planning Association, Hayat, and Nour El Hayat.

Last but not least, we are grateful to the Ford Foundation for their financial support of this study and to our colleagues at the Population Council for providing feedback and guidance throughout various phases of the study. 


\section{List of Acronyms}

\begin{tabular}{|c|c|}
\hline AIDS & Acquired Immune Deficiency Syndrome \\
\hline ARV & Anti-retroviral Drugs \\
\hline BBSS & Bio-Behavioral Surveillance Survey \\
\hline CAPMAS & Central Agency for Public Mobilization and Statistics \\
\hline FGD & Focus Group Discussion \\
\hline $\mathrm{FGM} / \mathrm{C}$ & Female Genital Mutilation/Cutting \\
\hline FSW & Female Sex Worker \\
\hline HIV & Human Immunodeficiency Virus \\
\hline IDI & In-depth Interview \\
\hline $\mathrm{KI}$ & Key Informant \\
\hline KPs & Key Populations \\
\hline MAG & Married Adolescent Girl \\
\hline MoHP & Ministry of Health and Population \\
\hline MSM & Men Who Have Sex with Men \\
\hline MWID & Men Who Inject Drugs \\
\hline NAP & National AIDS Program \\
\hline NGO & Nongovernmental Organization \\
\hline PLHIV & People Living with HIV \\
\hline PWID & People Who Inject Drugs \\
\hline SC & Street Children \\
\hline $\mathrm{SRH}$ & Sexual and Reproductive Health \\
\hline STIs & Sexually Transmitted Infections \\
\hline SYPE & Survey of Young People in Egypt \\
\hline VCT & Voluntary Counseling and Testing \\
\hline YFCs & Youth Friendly Clinics \\
\hline
\end{tabular}




\section{Executive Summary}

Young people aged 15-24 years constitute about one-quarter of Egypt's population of 90 million. The HIV prevalence rate among the general population is low $0.013 \%$ in the adult population in 2014), however, there are reports suggesting an increase in the number of HIV infections among young people (1524). Socio-cultural taboos around discussing sexuality in Egypt's conservative society and stigma associated with HIV/AIDS along with a lack of reliable data have limited our understanding of the HIV situation among Egyptian youth. The overall objective of the current study is to provide an evidence-based description and interpretation of the HIVrelated risks and vulnerabilities faced by different subgroups of youth in Egypt.

This study is part of a six-country study that was conducted by the Population Council in Egypt, Kenya, Nigeria, Senegal, South Africa, and Uganda. The study examines social, economic, cultural, and legal factors that may contribute to youth's increased vulnerability to HIV and documents the situation of the policy and programmatic responses. The Egypt component of the study involved: (1) a desk review of the literature, laws, policies, and strategy documents pertaining to HIV risk-taking and health-seeking behaviors of young people in Egypt; (2) in-depth interviews (IDIs) with key informants and stakeholders who are involved in programs that support youth sexual and reproductive health; (3) focus group discussions (FGDs) with male and female young people aged 15-18 years, 1824 years and HIV-positive male and female youth; (4) IDIs with male and female youth belonging to high-risk groups, namely people who inject drugs (PWID), street children (SC), married adolescent girls (MAGs), female sex workers (FSWs), and men who have sex with men (MSM).

The study identified a number of social, economic, cultural, and legal factors that may increase vulnerability of Egyptian youth to HIV. Poverty, unemployment, delayed marriage and gender inequality are examples of factors that increase young people's risktaking behavior and hence vulnerability to HIV. Knowledge of HIV modes of transmission and condom use are both very low among the Egyptian public. Laws and policies that discriminate against key populations (KPs) (e.g., MSM, PWID, and FSWs) and people living with HIV (PLHIV) may discourage those groups from seeking health care or HIV testing and HIV care and treatment services. Moreover, stigma and discrimination against PLHIV and KPs by society and healthcare providers keep those groups "underground." In the meantime, the Bio-Behavioral Surveillance Survey (BBSS) showed that key populations were engaged in multiple risk behaviors and have linkages to the general population through marriage and/or sexual relations.

HIV prevention programs for young people are quite limited apart from awareness raising activities that are conducted by the National AIDS Program (NAP) and a few initiatives that are implemented by local NGOs with international support. Several of those NGOs offer harm-reduction programs whereby KPs receive health services, 
counseling, and condoms/sterile syringes. However, HIV prevention programs face a number of challenges due to dwindling funds, conservative social norms, discriminating laws and policies, underutilization of services and lack of coordination among various stakeholders.

The report concludes with the following policy recommendations:

- Raise public awareness of HIV and its modes of transmission and address misconceptions about the disease and PLHIV;

- Encourage parents to discuss sexual and reproductive health (SRH) topics, including HIV, with their adolescent children;

- Use appropriate communication channels to convey information on youth SRH and HIV prevention to various subgroups of young people;
- Actively reach out to adolescent girls in rural areas as they tend to be secluded and have no access to information;

- Integrate SRH services for young people within primary healthcare services;

- Scale up harm-reduction services for high-risk groups into more geographical areas and expand scope of programs to include social, economic, and legal empowerment of KPs;

- Revisit laws and policies that discriminate against women, young people, PLHIV, and high-risk groups;

- Conduct more quantitative research to better understand sexual behaviors of various subgroups of young people; and

- Reform national policies to achieve more social and economic justice and to enable young people to take greater control over their lives. 


\section{Introduction}

With a population of 90 million people, Egypt is the country with the largest population in the Middle East North Africa (MENA) region. Egypt is at a stage in its demographic transition in which the proportion of youth in the population increases significantly compared to other age groups (Population Council 2010). Young people aged 15-24 years constitute about one-quarter of the population, while those aged 10-29 comprise $40 \%$ of the total population (CAPMAS 2011). This huge percentage of the population could present a demographic opportunity depending on how well the government invests in social, economic, and political institutions that meet the needs of young people (Assaad and Roudi-Fahimi 2007).

Egyptian youth have occupied a center stage position since the January 25th, 2011 revolution when they voiced their demands for "bread, freedom and social justice." Despite their optimism about a better future, young people in Egypt face a number of socioeconomic challenges due to low quality of education, high unemployment rates, and delayed family formation. Socially, they are caught between the deeply engrained norms and values of Egyptian society and new ideas and more liberal values to which they are increasingly exposed through mass media and the internet (Roudi-Fahimi and El-Feki 2011). On health issues, young people are exposed to risks of cardiovascular disease, obesity, road accidents, violence, and others (Ismail, Abdel-Tawab and Sheira 2015).

Little is known about Egyptian youth with regard to HIV risk. Data from the MENA region suggests an increase in the number of HIV infections, especially among youth. The number of adults and children living with HIV increased from 180,000 in 2001 to 240,000 in 2014 (UNAIDS 2015). Young people, especially young women, are at the center of the epidemic. Young people aged 15-24 account for nearly a quarter (23 percent) of adults aged 15 and above living with HIV (UNICEF 2011) while, $7 \%$ of PLHIV were adolescents aged 10-19 (UNICEF 2013).

In Egypt, HIV prevalence rates among the general population are quite low $(0.013 \%$ in the adult population in 2014). However, the National AIDS Program (NAP) has noticed an increase in the number of HIV infections among young people. Of 3,733 young people 15-24 years who underwent voluntary counseling and testing in 2013, 13.5\% were positive for HIV (NAP 2014). However, sociocultural taboos around discussing sexuality in Egypt's conservative society and stigma associated with HIVIAIDS along with a lack of reliable data have limited our understanding of the HIV situation among Egyptian youth. With this lack of knowledge, it would be difficult for Egyptian policy makers and program planners to design effective policies and programs to halt the spread of HIV infection among young people.

The overall objective of the current study is to provide an evidence-based description and interpretation of the HIV-related risks and vulnerabilities faced by different subgroups of youth in Egypt. The study examines social, economic, cultural, and legal factors that may contribute to youth's increased vulnerability to HIV and documents the situation of the policy and programmatic responses.

The ultimate goal is to provide Egyptian stakeholders with empirical evidence to support informed decision making related to youth sexual and reproductive health and to 
allow for the development and implementation of programs and policies that will reduce the number of new HIV infections, especially among young people who are the country's future.

This document uses the terms youth and young people interchangeably. They both refer to the age group 15-24 years unless otherwise specified.

\section{Methods}

This study is part of a six-country study that was conducted by the Population Council in Egypt, Kenya, Nigeria, Senegal, South Africa and Uganda to provide an evidence-based description and interpretation of the HIVrelated risks and vulnerabilities faced by different subgroups of youth across Africa. The study examined HIV-related national policies, programs, and laws; HIV-related risks and vulnerabilities of youth within the sociocultural context of each country. In addition, qualitative data were collected from youth and key institutional stakeholders to document the extent to which youth are addressed and involved in national programs around HIV prevention. ${ }^{2}$

This report presents results of the Egypt component of the study in detail. The Egypt component of the study involved the following: (1) a desk review of laws, policies, and strategy documents in addition to a review of relevant literature on factors associated with HIV risk-taking and healthseeking behaviors of young people in Egypt; (2) 21 in-depth interviews (IDIs) with key

\footnotetext{
${ }^{2}$ For a synthesis of findings from the six country study, please check the report "HIV/AIDS vulnerabilities, discrimination, and service accessibility among Africa's youth: Insights from a multi-country study."

http://www.popcouncil.org/uploads/pdfs/2014HIV_SixCountry YouthFinalReport.pdf
}

informants and stakeholders who are involved in programs that support youth sexual and reproductive health, (3) eight focus group discussions (FGDs) with male and female young people aged 15-18 years, 18-24 years, and HIV positive male and female youth (i.e. two FGDs per group), (4) 28 IDIs with young people belonging to high-risk groups, namely men who inject drugs, women who inject drugs, male and female street children (SC), married adolescent girls (MAGs), female sex workers (FSWs), and men who have sex with men (MSM).

Key informants and stakeholders who were eligible for in-depth interviews included program managers, peer educators, HIV service providers and legal advocates as well as representatives of key international and national organizations engaged in HIV response in Egypt. They were directly approached by a Population Council Program Officer, who explained the study to them over the phone. Those who gave provisional approval were interviewed in their office after obtaining their informed consent.

Male and female young people (15-18 years and 18-24 years) were recruited through local NGOs that offer awareness-raising activities to young people. NGO staff briefly explained the study to eligible young people and their parents (for those who were under 18). Young people and parents who gave initial approval were then approached by the interviewer who further explained the study to them, obtained their informed consent, and invited them to FGDs.

Young men and women who were HIV positive were recruited through local NGOs that provide harm-reduction services or services to PLHIV. 
NGO staff briefly explained the study to young PLHIV in person or over the phone. Those who expressed provisional interest were invited to come to the NGO on the day of the FGD when they were introduced to the researcher who further explained the study to them and conducted FGD with them after obtaining their informed consent. All young PLHIV were above 18 , hence parental consent was not needed.

The same procedure was followed for recruiting PWID, MSM, FSWs, MAGs, and male and female SC who were all recruited through local NGOs. For MAGs who were below 18, permission of husband was sought (as a courtesy) by NGO staff. For street children who were under 18, consent of the head of the NGO was obtained as a proxy for their guardian.

Interviews with KIs covered resource allocations to youth dimensions of the HIV response, policy and service delivery gaps, social and legal barriers to youth access to comprehensive HIV services, and recommendations on how to better target HIV/SRH programs and services to youth.

FGDs and IDIs with young people, young PLHIV, and key populations documented experiences and lessons learned from young people impacted by HIV as well as challenges they faced while trying to access HIV and related SRH services.

The study protocol was reviewed by the Population Council's Institutional Review Board (IRB), National AIDS Program (NAP) officials, as well as key stakeholders in Egypt. Data were collected by trained male and female interviewers who were closely monitored by Population Council researchers. Strict measures were followed for protection of research participants. 


\section{Results}

\section{HIV prevalence and knowledge}

With an HIV prevalence rate of 0.013 percent, Egypt is considered a low-prevalence country. Although the situation of HIV/AIDS in Egypt is not yet alarming, several factors are predictive of an increase in HIV prevalence in the coming years, especially with low levels of HIV knowledge among the general public, along with low rates of condom use. Also, while risk behaviors associated with HIV infection exist in Egyptian society; their extent is unknown due to socio-cultural taboos around sexuality and stigma around high-risk groups. Moreover, there is a potential for a more expansive epidemic due to pervasive risky behaviors among key populations (KPs) and links between KPs and the general public (Setayesh, El Feki, and Ashford 2014). This section provides background data on the situation of HIV/AIDS among the general public as well as selected high-risk groups.

UNAIDS estimates that in $2014,8,800$ people were living with HIV in Egypt with a higher proportion of male adults $(6,100)$ compared to female adults $(2,400)$ being infected. There were 1,200 new cases of HIV, a higher number compared to previous years, and fewer than 500 deaths due to AIDS (UNAIDS 2014). NAP statistics indicate that the population group most affected by HIV is the 20-45-year age group, which represents $74 \%$ of all reported cases. Women account for $20 \%$ of all reported cases, while youth aged 15-24 years account for $14 \%$. Of the total detected cases in $2010,46 \%$ were caused by heterosexual transmission, $21 \%$ by homosexual transmission, and $28 \%$ were through drug use (NAP 2015).
The 2015 Egypt Health Issues Survey revealed that $66 \%$ of women and $79 \%$ of men aged 15-49 had heard of HIV/AIDS. Knowledge of AIDS is lowest among women and men aged $15-19 \quad(50 \%$ and $57 \%$, respectively), women and men with no education ( $35 \%$ and $53 \%$, respectively), and women and men in the lowest wealth quintile ( $48 \%$ and $67 \%$, respectively). Knowledge of HIV preventive methods (i.e., using condoms every time someone has sexual intercourse and having one sex partner who is not infected and does not have other sex partners) is lower among women than men aged $15-49$ ( $27 \%$ and $41 \%$, respectively) and lowest among young women and men 15-19 (16\% and 25\%). Comprehensive knowledge about HIV is extremely low among women and men $15-49$ ( $6.2 \%$ and $9.5 \%$, respectively) and even lower among young women and men $15-24$ (4.1\% and 6.6\%) (Ministry of Health and Population, El-Zanaty and Associates, and ICF International 2015b). ${ }^{3}$

Furthermore, the Survey of Young People in Egypt (SYPE) revealed that $73.2 \%$ of respondents $13-35$ had heard of HIV/AIDS, with higher percentage of males (77.4\%) than females (68.8\%) and among those in higher wealth quintiles. Among those aged 13-17, only $59.6 \%$ had heard of HIV. Surprisingly, in comparison to SYPE 2009 results, a lower proportion of respondents in 2014 had heard

\footnotetext{
${ }^{3}$ Comprehensive knowledge of HIV means knowing that consistent use of condoms during sexual intercourse and having just one uninfected faithful partner can reduce the chance of getting the AIDS virus, knowing that a healthylooking person can have the AIDS virus, and rejecting two common local misconceptions about transmission or prevention of the AIDS virus.
} 
of HIV. Among respondents who had heard about HIV, 93.7\% knew that it can be transmitted sexually and $89.2 \%$ knew that it can be transmitted through contaminated blood, while $79.9 \%$ knew that it can be transmitted through sharing a needle (Ismail, Abdel-Tawab and Sheira 2015).

Despite low prevalence of HIV among the general population, a concentrated HIV epidemic exists among key populations in Egypt, namely men having sex with men (MSM) and injecting drug users/people who inject drugs (PWID) as reported in the 2010 Bio-Behavioral Surveillance Survey (BBSS) (FHI/MoH 2010). The BBSS reported on HIV prevalence rates in four key populations. PWID had the highest HIV population prevalence rate $(6.8 \%$ in Cairo). Similarly, MSM in Alexandria had a prevalence rate of $5.9 \%$. The BBSS also tested street children and found that street boys and girls had the same prevalence of $0.5 \%$. It is worth noting that none of the female sex workers in the BBSS sample tested positive for HIV (FHI/MoH 2010).

A large percentage of KPs had heard of HIV, however many of them were ill-informed about the modes of transmission and preventive methods. A remarkable $89 \%$ of FSWs had heard of HIV, but much of their information was false. For instance, $56.2 \%$ of FSWs believed that a healthy looking person could not be HIV positive. There was also a large gender gap among street children in which only $28.5 \%$ of street girls had heard of HIV compared to $69.5 \%$ of street boys. Almost all MSM in Cairo and Alexandria have heard about HIV, but only $33.3 \%$ of MSM in Luxor. Similarly, almost all of men who inject drugs (MWID) had heard of HIV (FHI/MoH 2010).
BBSS documented multiple risk behaviors among KPs in Egypt. Sharing needles in the past 30 days was a common practice among males who inject drugs in Alexandria and Cairo (40.5\% and $22.9 \%$, respectively). Additionally, around $3.0 \%$ and $30.4 \%$ of males who inject drugs reported condom use with regular noncommercial sex partners and nonregular, noncommercial sex partners, respectively (FHI/MoH 2010). Commercial sexual activity was practiced by one in three MSM in Cairo and Alexandria $33.2 \%$ and $31.8 \%$, respectively) and $92 \%$ of $\mathrm{MSM}$ in Luxor. Unprotected sex was common among MSM; $51 \%$ of MSM in Cairo, $34 \%$ of MSM in Alexandria, and $22 \%$ of MSM in Luxor reported condom use during commercial sex in the six months preceding the survey (FHI/MoH 2010). Unprotected sex was a common practice among FSWs; condom use with clients was very low as only one-quarter reported condom use during the last commercial sex act and $41.0 \%$ reported condom use at least once in the 30 days prior to the survey. In addition, a small minority (6.0\%) of FSWs reported using injectable drugs (FHI/MoH 2010).

The BBSS survey found that key populations had links to the general population through marriage or sexual relations. Almost half of males who inject drugs (45.1\%) and FSWs in Cairo $(45.5 \%)$ were currently married. Of respondents from the MSM demographic in Cairo, 40\% reported ever having sexual relations with women. The percentage goes up to $59 \%$ in Alexandria and $86 \%$ in Luxor (FHI/MoH 2010).

Street children (SC) are a population that is greatly marginalized and highly mobile. 
According to UNICEF, the number of street children in Egyptian cities is estimated to reach tens of thousands (UNICEF n.d.). In addition studies have shown that life on the streets exposes them to multiple risk factors and increases their vulnerability to infection with sexually transmitted infections including HIV. A study of street children in Cairo and Alexandria revealed that a considerable proportion of street children in Greater Cairo $(52 \%)$ and Alexandria (61\%) were engaged in multiple risky sexual behaviors including forced sex, unprotected sex, sex with multiple partners including commercial sex partners, and sex under the influence of drugs (Nada and El Daw 2010). Although $69.5 \%$ of street boys and $28.5 \%$ of street girls had heard of HIV, none of the sexually active street boys used condoms with commercial sex partners, while only $4.1 \%$ had used it with noncommercial sex partners in the last sexual encounter. Male-to-male sexual activity was reported by $44.2 \%$ of street boys $(\mathrm{FHI} / \mathrm{MoH}$ 2010).

\section{Socioeconomic,}

\section{Cultural and Legal Factors Influencing Youth Vulnerability to HIV}

Young people's sexual and reproductive health (SRH) behavior is shaped by the economic, social, and cultural context in which they are raised, including the powerful influence of religion and tradition (RoudiFahimi and El-Feki 2011). Living in a conservative predominantly Islamic society with a strong focus on family values, youth in Egypt are exposed to many protective factors against HIV. In the meantime, Egyptian youth are faced with several socioeconomic, cultural, and legal factors that may indirectly influence youth sexual

and reproductive health and consequently their vulnerability to HIV. This section provides an overview of those factors based on results of our literature review as well as qualitative research.

\section{Education}

Education provides an opportunity for young people to build their cognitive and social capital and acquire new skills that enable them to join the labor market and actively participate in public life. Young people who do not enroll in school have limited access to information on HIV, less social capital to draw on for information, and fewer skills to enable them to negotiate safe sex with their partners. Also, limited access to education undermines young people's job opportunities; hence they get trapped in a cycle of poverty which increases their exposure to risk factors (Afawubo et al. 2014).

Even though education is a constitutional right in Egypt and basic education is mandated by law, a substantial proportion of young people in Egypt never go to school or drop out of school. According to the Survey of Young People in Egypt (SYPE) conducted in 2014, almost all youth born in the 1990s had received some form of schooling (Krafft 2015). However, remarkable disparities in school enrollment exist by gender and region with females' age 18-24 being twice as likely to have never attended school (9.6\%) compared with their male counterparts (5\%). In addition, those living in rural regions (13\%), particularly in rural Upper Egypt and the Frontier Governorates have much higher 
never-attendance rates than their urban counterparts (4.2\%) (Krafft 2015).

Even among young people who complete their secondary education there are disparities in access to higher education. A compendium of papers that was developed by the Population Council showed that the odds of a student from a higher-income family enrolling in higher education are seven times greater than those of a student belonging to a lower-income family. It was also shown that the gap between male and female students in Egypt still exists especially in rural areas where male students are four times more likely to attend university than female students (ElBaradei 2012). Limited access to higher education deprives students from disadvantaged families of greater access to knowledge, increased skills acquisition, better job opportunities, as well as social mobility. All of the above factors may have implications for increased vulnerability to HIV.

\section{Employment}

Employment may be protective against HIV in several ways (Afawubo et al. 2014). One, as young people have jobs and make an income they can get married which provides an opportunity for them to practice sex in a socially sanctioned mode. Two, young men and women who are earning a living would not need to practice commercial sex in order to support themselves or their families. Studies found that female sex workers in debt are more likely to engage in risky sexual behavior and be exposed to sexual violence, increasing their risk for HIV (Reed et al. 2010). Moreover, employment enhances young people's self-esteem and fills up their time hence they would have less time to practice risky behavior.
Egypt is faced with the challenge of balancing the demographic opportunity of a large labor force with creating enough job opportunities to fit this growing need. Unfortunately, rates of unemployment are high among young people in Egypt, especially female. Unemployment rate among young people $15^{-29}$ years is $13.3 \%$ with remarkable differences between male and female youth (9.3\% for males and $32.3 \%$ for females). ${ }^{4}$ Unemployment rates increase with educational attainment, signifying that unemployment is a problem of educated youth and that the job market is not well matched for the skills of better-educated Egyptian youth. According to SYPE's 2014 data, $16.8 \%$ of male university graduates and $36.7 \%$ of female university graduates were unemployed (Roushdy and Selwaness 2015). Moreover, culture and patriarchal norms still pose important barriers to female labor market participation, with about $16.5 \%$ of young women mentioning that they do not want to work due to their parents' or spouse's refusal.

Even those who are fortunate enough to be employed may not be earning sufficient salaries to support them in starting a family. According to SYPE, a large proportion of working Egyptian youth have low-quality jobs and their wages are insufficient to support them in their transition to adulthood and family life (Roushdy and Selwaness 2015). In Egypt, the percentage of people who live below the national poverty line was 25.2\% in 2012 (UNDP 2014). A male street child participant indicated: "Here I am, a youth, who doesn't know what to do, or what

\footnotetext{
${ }^{4}$ We use the standard International Labor Office (ILO) definition of unemployment, which defines as unemployed all those who have not worked or been attached to a job during the week prior to the survey interview, were willing and available for work, and were actively searching for work.
} 
my future holds, and there's no money." Male Street Child

Poverty and unemployment prevent youth from fulfilling their sexual desires through socially sanctioned channels, i.e., marriage, as will be described later. Also, unemployment and poverty are often associated with a sense of helplessness and low self-esteem, and potential engagement in high-risk behaviors such as drug use or sex work (Afawubo et al. 2014; El-Bassel et al. 2014) Poor financial conditions and limited life skills, may force young women to exchange sex for money or favors. For married young women, financial dependency undermines their autonomy and negotiation power and hence they may continue in a marital relationship despite their awareness of their husband risky behavior (Oraby and Abdel-Tawab 2016).

\section{Migration}

Poor socioeconomic conditions and limited employment opportunities in Egypt drive many young people, especially men, to search for job opportunities in other countries. In 2012, $15 \%$ of Egyptian households had a returnee or a current family member working abroad (Wahba 2015). While remittances sent by those young people contribute to the Egyptian economy, there are reports of young men who acquired HIV infection while working abroad and who have passed on the virus to their wives. Very little research has examined migrant workers' risk behaviors while away from home, however, there is evidence of HIV infection in the Persian Gulf region among migrants from Egypt (Jenkins and Robalino 2003). In fact, a study conducted by Population Council researchers in India showed male outmigration to be the most important risk factor influencing the spread of HIV infection in rural areas (Saggurti et al. 2012). A recent study conducted by the Population Council revealed a number of risky behaviors among Egyptian migrants working in Western countries as well as those working in tourist resorts in Egypt (Oraby and Abdel-Tawab forthcoming). As men stay away from their families and become detached from the norms of home, they may engage in unprotected sex with sex workers or injecting drug use (UNAIDS 2012).

Moreover, political instability in the Arab region has resulted in an influx of forced migrants (refugees) from Iraq, Libya, Syria, Sudan, and other countries to Egypt. Very little research has examined sexual behavior or risks among forced migrants in Egypt. However, there are reports that some of those migrants, especially young women, are forced into non-consensual sex, commercial sex, or transactional marriages to overcome economic hardships thus are exposed to an increased risk of HIV (Setayesh et al. 2014i UNHCR 2014).

\section{Marriage}

Marriage is highly cherished in Egyptian society hence all young men and women in Egypt are expected to get married in their 205 or 305 as marriage could be protective against HIV if both partners are not practicing risky behaviors and neither of them is HIV positive. Egyptian law sets the minimum age of marriage at 18 for both men and women. Increased university enrollment and rising career aspirations have made many young men and women opt for delaying marriage (Roudi-Fahimi and El-Feki 2011). For other young men and women, delaying marriage is not a matter of choice but a result of inability to afford the costs of marriage. 
According to survey of SYPE 2014, on average marriage costs about 40,000 $\mathrm{E} f$ to those married after 2010. The median age of marriage in Egypt is now 25 for men and 20 for women. Delayed marriage has led many young men and women to go into a state of 'waithood' (Roudi-Fahimi and El-Feki 2011). According to one of our study participants:

"The whole idea is that young people cannot find jobs and cannot get married. They really don't know what to do."

\section{HIV positive male}

To circumvent the costs of marriage, while giving sexual relationships religious legitimacy, some young people resort to urfi marriage, which is an unregistered form of marriage. Usually a paper, stating that the two are married, is written and at least two witnesses sign it, they do not live together and the relationship is often kept secret from their families. A study involving 4,566 young males and females aged 18-30 years showed the prevalence of secretive Urfi marriage was $4 \%$ among the total population of youth and $6 \%$ among university students, despite social stigmatization of the practice (El-Tawila and Khadr 2004). Usually those marriages are kept as a secret and are not endorsed by the young couple's families (Roudi-Fahimi and ElFeki 2011). Social and legal constraints along with fear of being asked about their marital status can deter these young couples from seeking reproductive health services or even buying condoms.

At the other end of the spectrum are young women who get married at very young ages. According to the Child's Right Law a marriage contract cannot be registered for a man or a woman who is under 18 years of age. ${ }^{5}$ However, some families, especially in rural areas, bypass this law by following urfi or sunnah marriages, which do not require registration or filing of official documents. According to SYPE 2014, 21\% of married women (ages 25-29) were married before age 18 (Sieverding and Ragab 2015). The main reasons for early marriage are poverty, gender norms which discourage girls' participation in public spheres, and parents' desire to protect the girl's reputation and virginity. Girls who marry in their teens are typically more socially isolated, lack knowledge about family planning and reproductive health services, and may also lack the power to make decisions about their own health (Roudi-Fahimi and El-Feki 2011).

A recent survey of married adolescent girls (MAGs) in rural Upper Egypt showed that more than one third of married adolescent girls in Assiut and Sohag were exposed to gender-based violence, mainly by their husband (Population Council and Assiut University, forthcoming). Another study showed that those girls are often exposed to forced sex and other forms of sexual violence (Darwish et al. 2013). With such low negotiation power, limited access to reproductive health information and services, along with exposure to various forms of violence, MAGs may be at high risk of exposure to HIV.

One group of adolescent girls that is at particularly high risk for HIV infection is "summer brides" (i.e., girls who are engaged in transactional marriages). These are young women from low-income families who are married off by their parents to Arab tourists who visit Egypt for the summer. Those marriages are often very short-lived and

${ }^{5}$ Article 31, law number 126 (2008). 
recurrent, with some girls reported to have been married up to seven times. Very little information is available on this group of brides apart from anecdotes highlighting improper treatment by their husbands or legal problems resulting from lack of documentation (Elsamaloty and El-Zanaty 2010).

The Egyptian legislature has issued laws regulating marriage of Egyptian girls to nonEgyptian men ${ }^{6}$ as well as laws forbidding human trafficking. ${ }^{7}$ However, the above laws are rarely enforced but are often circumvented through urfi or sunnah marriages which are not registered. Moreover, Egyptian law does not incriminate urfi or sunnah marriages for under-age girls or girls marrying non-Egyptian men.

\section{Gender norms}

Inequitable gender norms may increase the risk of HIV as they affect access to information, skills, or SRH services as well as the ability to negotiate safe sex (Richardson et al. 2014). Egyptian society is a patriarchal society that largely restricts women's role to the domestic sphere, hence women in conservative parts of the country are not expected to go to school, participate in the labor force, or play an active role in their communities.

The family honor rests with the woman's conduct and her ability to maintain their chastity, and it is men's responsibility to protect the family honor. Thus, men (husbands or brothers) have a right to use violence to discipline a disobedient wife or

\footnotetext{
${ }^{6}$ Revision \# 103 (1976) for article 5 of law number 68 (1947). ${ }^{7}$ Egyptian anti-trafficking law 64/2010 - Articles 1, 2, 3, 4, and 5.
}

sister or even kill their wife or sister if they suspect her misconduct. According to SYPE 2014 results, $70.9 \%$ of male youth and $58.4 \%$ of female youth $15^{-29}$ years agreed that a man would be justified in beating his wife if she "talked" to another man (Sieverding and Ragab 2015).

By virtue of the same gender norms, men are socialized to be masculine, strong, and to provide for their families. Moreover, they are encouraged to be risk-taking, thus some of them may engage in risky behaviors including drug use and unsafe sex. Young men's sexual behavior outside the context of marriage is tolerated on the grounds that they have no other means to satisfy their sexual needs (for those who are not married) or they are not finding happiness with their wives (for those who are married).

A flagrant example of gender inequality is female genital mutilation/cutting (FGM/C). According to SYPE 2014, four out of five young women 15-29 have been exposed to FGM/C (Ismail, Abdel-Tawab and Sheira 2015). FGM/C is practiced to curb young women's sexual desire, and thus protect her from inappropriate behavior, to abide by religious traditions, to ensure girls' cleanliness, and to follow cultural traditions (Tag-Eldin et al. 2008). Unlike male circumcision which has a protective value against HIV/AIDS, FGM/C puts girls at a higher risk of contracting HIV due to its association with infections and other complications (Abu-Raddad et al. 2010). Also, FGM/C has been widely associated with decreased sexual responsiveness among women (real or imagined) which may give some married young men justification to seek extramarital relations to fulfill their "unmet needs." 
For the most part, the Egyptian legal system does not promote gender inequality, but it does not forbid it. Egyptian law considers wife battering as a justification for divorce, yet very few women exercise that right due to their economic dependency on their husband. ${ }^{8}$ Also, Egyptian law considers violence that leads to an injury a crime; however, women who are admitted to the hospital as a result of husband violence are rarely reported to police. ${ }^{9}$

However, Egyptian law clearly discriminates between men and women in adultery crimes where men are accused of adultery only if they have sex in the marital home, while women are accused if they are suspected of having sex with a man other than their husbands. ${ }^{10}$ Moreover, a man who kills his wife or sister to 'protect family honor' gets up to seven years in prison while a woman who kills her husband due to adultery gets up to 25 years in prison.

These harmful gender norms and legal disparities place a burden on both young men and women and increase their risk for HIV infection. Women's economic dependence on their husbands undermines their bargaining power. Fear of exposure to violence and unawareness of their sexual rights make young women succumb to unprotected sex with their husbands/sex partners who may be engaged in risky behavior (UNAIDS 2013). On the other hand, societal acceptance of and complacence with men's expressions of sexuality and masculinity may encourage young men to engage in risky behaviors such as unprotected sex, drug use, or having multiple

\footnotetext{
${ }^{8}$ Article 6 f Law for year 1929 (Fault-based divorce)

${ }^{9}$ Articles 241-243 of Penal Code Number 58 (1937)

${ }^{10}$ Articles 273-277 of Penal Code and Prostitution Law No. 10/1961.
}

sex partners. To abide by the image of strength and masculinity, men may not seek health care (e.g., counseling and testing), thus increasing their risk for HIV (Betron et al. 2012).

\section{Societal norms around sex and sexuality}

Like many countries in the MENA region, sexuality is a taboo topic in Egypt. Sexual relations outside the context of marriage are strictly prohibited, especially for young women. Those strict social norms around practice of sex outside the context of marriage may have had a protective role against HIV infection. However, sexual relations outside the context of marriage do exist but their types and scope are not known due to a paucity of research on this topic. As mentioned above, KPs who practice risky sexual behaviors are linked to the general population through marriage or extra marital sexual relations. As to the general population of youth, SYPE 2014 indicated that $11.3 \%$ of young men and women aged 13-35 knew "other" young people who were in a relationship with the opposite sex. Out of those who answered yes, $18.9 \%$ also indicated that these relationships were intimate (Sieverding and Ragab 2015). It is noteworthy that those figures may be an underreporting as SYPE interviews took place in respondents' homes, thus some young people may have been afraid of being overheard by family members.

There are also reports of young people, especially women, engaging in non-vaginal sex (e.g. oral and anal sex) in order to preserve their hymen (El-Kak 2013). While no research has documented such practices in Egypt, one study in Lebanon (Ghandour et al. 
2014) documented such practices among university students.

Among sexual acts, unprotected receptive anal sex is associated with the highest risk of HIV transmission (Patel et al. 2014).

Social norms also govern sexual relations within marriage where the husband is expected to be proactive and aggressive (if necessary), while the wife is supposed to be submissive and responsive to her husband's sexual needs. A woman who refuses to have sex with her husband is considered "sinner." SYPE 2014 revealed that $41.8 \%$ of young boys and $31.3 \%$ of young girls ages $15-29$ years agreed that the husband is justified in beating his wife if she refuses him sex (Sieverding and Ragab 2015). Moreover, EDHS 2014 revealed that $25.2 \%$ of married women 15-49 were exposed to some form of physical violence while $4.1 \%$ were exposed to forced sex (Ministry of Health and Population, El-Zanaty and Associates, and ICF International 2015a). The above social norms may lead women to succumb to sexual relations with their husband even when they suspect that he is practicing high-risk behavior.

The Egyptian legal system does not address the issue of rape within marriage. In fact, the law does not differentiate between marital and extramarital rape. ${ }^{11}$ However, very few judges (the vast majority being male) in Egypt would consider forced sex by husband as a type of rape.

Societal norms that place great emphasis on achieving sexual pleasure for the husband have negative repercussions for condom use as condoms are believed to reduce sexual pleasure. Moreover, condom use is believed

\footnotetext{
${ }^{11}$ Article 267 of Penal code number 58 (1937).
}

to be haram (not sanctioned by Islam), harmful to a man's health, undermining to his masculinity, or even fatal (Abdel-Tawab et al 2015). Not surprisingly, EDHS 2014 revealed that less than one percent of female contraceptive users (15-49 years) use condoms (Ministry of Health and Population, El-Zanaty and Associates, and ICF International 2015a).

Taboos around sex and sexuality also extend to open discussion of this topic, especially with young people. There is a widely held misconception that talking with young people about sexuality could encourage them to practice sex. Thus, parents seldom discuss any information related to sexuality or even reproductive health with their children. In the meantime, other venues that educate young people about sexuality or protection against HIV barely exist (as will be discussed in subsequent sections). This has been confirmed by the findings of our qualitative research as per the quotes below.

"The problem is religious strictness in both Christianity and Islam and trying to deny such facts." HIV positive male

"The community does not accept discussion of these topics (SRH)." Female who injects drugs, Cairo

\section{Stigma and discrimination}

\section{HIV-related stigma}

HIV infection is highly stigmatized in Egyptian society. It is perceived to be a result of engaging in unacceptable behaviors such homosexuality, drug use and extramarital sex. Thus, PLHIV are perceived as people who are disobedient to God and hence deserve 
punishment (Khattab and El Guneidy 2010). According to EDHS 2014, only 50.8\% of women who have heard of HIVIAIDS are willing to care for a family member with AIDS in their own home and only $19.2 \%$ would buy fresh vegetables from a shopkeeper who has the AIDS virus (Ministry of Health and Population, El-Zanaty and Associates, and ICF International 2015a).

Attitudes of young people are no more accepting of people living with HIV; SYPE 2014 showed that $17.1 \%$ of young men and women (ages 15-29) are willing to interact with someone living with HIV (e.g., shake hands or ride in a car with them) (Ismail, Abdel-Tawab and Sheira 2015).

Discrimination can occur at all levels in the daily life of people living with HIV. There are reports of PLHIV who have been terminated from their jobs, evicted from their homes, and denied medical treatment or child custody (Khattab and El Guneidy 2010; Oraby and Abdel-Tawab 2014).

In our qualitative study one young woman living with HIV said the doctor and nurse reprimanded her when they learned that she was pregnant by telling her, "You are a problem and your husband is a problem. Why do you bring another problem; you should go and kill yourself." In a similar vein, one young male living with HIV said, "I would kill myself if people in my neighborhood found out that I was HIV positive."

This widespread stigma and discrimination have serious repercussions on HIV prevention. Very few young people undergo HIV testing for fear of facing implications of a positive result and associated social stigma. Moreover, those who test positive refrain from telling their families, sex partners, or drug partners and fail to take preventive measures, thus exposing more people to infection. According to BBSS 2010, out of the $69.5 \%$ of street boys that have heard of HIV, only $5.8 \%$ were ever tested. Moreover, $89 \%$ of FSWs had heard of HIV, but only $3.4 \%$ of the FSWs interviewed were ever tested. Only $2 \%$ of MSM in Luxor who had heard of HIV had undergone testing. Finally, only $9.5 \%$ of the MWID who have heard of HIV have received testing for HIV (FHI/MoH 2010).

"They [street children] don't go because the person who is taking the test will be overwhelmed with fear. For example, if $\mathrm{Mr}$. Ahmed tells me I have the virus I will be frightened and everyone will hate me and find out that I have AIDS.... Nowhere in Egypt treats AIDS. " Male Street Child

Even though Egypt is a signatory to almost all international laws and agreements related to human rights such as right to life, protection of privacy, right to health care, right to free movement, right to work, and right to nondiscrimination among others, some laws and policies in Egypt discriminate against PLHIV. Based on Ministerial Decree Number 435 that was issued in 1986 managing cases of HIVIAIDS should follow the same precautions taken with infectious diseases such as cholera or plague. A doctor who identifies a case of HIV therefore is required to inform health authorities and provide all of the information that would allow them to locate the patient and take necessary measures to prevent the spread of the disease, including isolation of the patient. Even though recent guidelines issued by the National AIDS Program (NAP) emphasize that PLHIV should be treated with dignity, not be isolated, and their data should be confidential, many healthcare providers and security officials are not aware of those 
guidelines and thus treat PLHIV with disrespect and deny them services.

Article 9 of the Egyptian Constitution grants all citizens the right to work with no discrimination. However, there are several ministerial decrees that make it hard for PLHIV to exercise that right. According to those decrees PLHIV cannot work in some Arab countries that require an HIV test. Also, once classified as having an infectious disease, PLHIV are not allowed to work in the food industry, the army, the police, or the judiciary. ${ }^{12}$

On the other hand, those who are working in jobs other than the above listed ones are subjected to termination if their status is known, even though Egyptian law does not grant employers such right.

"The law does not say [that employers] have a right to fire [PLHIV] but for a person to get his rights he has to file a lawsuit and announce that he is infected which of course he will not do." Head of an NGO that provides services to PLHIV

\section{Stigma against high-risk groups}

Stigma and discrimination also extend to groups who practice behaviors that defy social norms. High-risk groups who practice illicit behaviors such as drug use, homosexuality, or sex work are looked down upon by society and are even exposed to harassment or legal prosecution. Fear of discrimination, harassment, or prosecution prevents young men and women in those groups from revealing their high-risk behavior or seeking health care. A study of

\footnotetext{
${ }^{12}$ Article 21 of Law on Infectious Disease.
}

MSM self-perceptions and health-seeking behavior revealed MSM's mistrust of healthcare providers and suspicions that they would prescribe 'wrong medicines' to MSM if they revealed their homosexual behavior to them (Abdel Mawgood 2013).

Several of our study participants who practice high-risk behaviors confirmed their exposure to harassment by authorities or bad treatment by healthcare providers. They indicated that they would prefer to go to private facilities due to relatively better personal treatment and care.

"They treat us like garbage in the health unit. When we need health services, we choose what we can pay for and I do not go except if I have [genital] itching." Female street child, Alexandria

"When I went to the health center with one of my friends who had red spots, I was afraid that she had AIDS. Once we asked them about AIDS they started insulting us saying 'go to the person who did that to you to help you get treatment' and they made a scene in front of the whole center so we left." FSW, Cairo

There are wide variations in the legal status of high-risk groups under Egyptian law. Drug use is punishable by up to 15 years in prison if a person is caught carrying or using drugs at the time of arrest or if $s / h e$ is carrying instruments used for injecting drugs. However, if a person reports to a healthcare provider that $s /$ he is a drug user, the former is treated as a patient and is referred to a rehabilitation center. ${ }^{13}$ For homosexuality there is no article in Egyptian law that explicitly criminalizes homosexuality,

\footnotetext{
${ }^{13}$ Articles 37 A and B of Drugs Law.
} 
however legal authorities often consider homosexuality as a form of prostitution and debauchery, which are punishable by Egyptian law by up to three years in prison. ${ }^{14}$ Commercial sex work is criminalized by Egyptian law by up to three years in prison for both workers and dealers in sex work, but it does not punish customers of sex workers. This discrimination in favor of men may indirectly encourage some men to have preand/or extramarital relations with sex workers, thus exposing themselves, their current or future wives, and their children to the risk of HIV.

Street children are considered vulnerable to delinquency, so police authorities take several measures to reintegrate them into society, including returning them to their parents or admitting them into rehabilitation or vocational training centers. Street children tend to avoid police for fear of being accused of crimes that they did not commit (Nada and El Daw 2010). Moreover, not having identity papers prevents them from interacting with formal institutions or seeking health care. .

\section{HIV Prevention Services for Young People}

Sources of information on HIV modes of transmission or prevention are quite limited for young people. Parents do not discuss sexual or reproductive health issues with their adolescent boys and girls (Ismail, AbdelTawab and Sheira 2015; Hassan 2013; Yousri and Mamdouh 2013). Even though providing $\mathrm{SRH}$ education in schools might be costeffective as the majority of Egyptian adolescents are enrolled in school, Egyptian students have very little access to quality

\footnotetext{
${ }^{14}$ Article 10 of Prostitution Law (1961).
}

SRH education mainly because teachers are not adequately trained to provide this information, are shy about providing it, or feel pressure by parents to gloss over these topics (Geel 2013).

Not knowing where to go for SRH information, young people may rely on the internet or their peers as noted by one of our MSM. "I always go to the internet even though we were taught these things in preparatory school but it wasn't clearly explained, particularly methods of protection and how diseases are transmitted."

Similarly, SYPE 2014 demonstrated that the most common sources of SRH information for youth were mass media (60.9\%), followed by school (12.2\%) and friends (6.1\%) (Ismail, Abdel-Tawab and Sheira 2015).

However, sources available for young people often provide inaccurate information. For example, one Arabic website mentioned that HIV could be transmitted through saliva or a toothbrush (Benikrane 2013). Young people who become sexually active without accurate information on reproductive health risk having unintended pregnancies, unsafe abortions, and acquiring sexually transmitted infections (STIs) including HIV (DeJong et al. 2007). The following comment made by one our study participants supports this assertion.

"If correct information had been available for me, I would not have contracted this disease (HIV). " HIV positive male at FGD

Primary care services at Ministry of Health and Population facilities are structured around vertical programs like family planning, maternal and child health care, immunization, and school health among others. None of the above programs targets youth or provides education and counseling 
on HIV. Although a premarital exam is mandated by law, research suggests that those services are not taken seriously by providers or clients and rarely include SRH counseling (Abdelbaqy 2013). Several of our study participants confirmed the lack of SRH services for youth.

"Societal norms do not perceive of youth as having health needs and specifically $R H$ needs until after they get married." NGO official

"Even the law mandating a premarital exam does not include tests such as hepatitis $B$ and $C$, let alone AIDS. Even more importantly, you buy the certificate for E£2o; you don't actually do the tests." HIV positive male at FGD

Most HIV prevention work is implemented by the National AIDS Program of Ministry of Health and Population. The NAP offers awareness-raising activities through seminars and educational campaigns that target the general public including men, women, young people, and other population groups. The NAP also trains healthcare providers in the clinical care of PLHIV and combating stigma and discrimination. Furthermore, the NAP provides voluntary counseling and testing (VCT) services free of charge through VCT centers in most governorates. Service units are supposed to provide pre- and post-test counseling sessions to clients coming for HIV testing while observing the anonymity of tests and confidentiality of results. Also, the NAP is responsible for administration of ARV to cases with confirmed HIV diagnoses, and prevention of mother-to-child transmission services as well as referral of PLHIV to curative care at fever hospitals.

Although our study participants appreciated the free services that are offered by NAP (as noted in the quote below), questions were raised about the efficacy of awarenessraising seminars to the general public. According to several of our key informants, when resources are limited and infections are concentrated within certain population groups, it is more cost-effective to focus activities on key populations who are at highest risk for infection.

"I did an HIVIAIDS test at the center in the Ministry....It was for free and I was very happy with it." FSW, Cairo

SRH information and services to young people, including key populations and PLHIV, are mostly provided by local NGOs which have established "youth friendly" clinics (YFCs). There is a total of approximately 30 such clinics nationwide that are supposed to provide SRH information and services to young people in a private and comfortable setting. Most of these clinics have peer educators who conduct seminars at youth hot spots and refer young people who have questions or health problems to the clinic.

Besides their limited number and restriction to large urban areas, there are reports suggesting that these clinics are severely underutilized. Fear of social stigma, young people's shyness about discussing SRH matters, and insufficient advertising are a few of the factors underlying low utilization of YFCs (Soliman et al. 2009; Mossa et al. 2013). Questions have also been raised about the quality of services that are offered by YFCs as insufficient information about protection against STIs, judgmental treatment by providers and blatant breaches of clients' privacy have been documented (EI Damanhoury and Abdelhameed 2013). Moreover, 
"No one really knows anything about the youth-friendly clinics or their role. If I asked someone on the street, they wouldn't know anything about it." Male aged 18-25 years at FGD

"I feel comfortable when I come here (NGO clinic) and speak to the service provider in the NGO. She understands me very well, and understands youth needs, and she doesn't leave us until she makes sure that we all understand well." MAG participant in Cairo

People at high risk for contracting HIV such as MSM, PWID, FSWs, and street children receive "harm-reduction" services through local NGOs. There are approximately 15 harm-reduction centers nationwide.

Services delivered at these harm-reduction interventions are anonymous and free of charge. They include health education and counseling on safe sex and safe injection, HIV counseling and testing, in addition to distribution of condoms and sterile needles. Harm-reduction centers utilize outreach workers from the same target group and word of mouth of their clients to recruit new clients. Outreach workers are MSM, FSWs, and former drugs users who can easily establish rapport with clients and gain their trust. NGO centers that provide harmreduction services are mainly located in Cairo and Alexandria with a few recently established centers in Upper Egypt.

Our study participants commended services they received at those centers, particularly the safe and friendly atmosphere as well as the receipt of condoms and/or syringes free of charge. One MSM appreciated the fact that those centers do not ask clients for their personal data. However, several participants confirmed that they would only go to services that were located away from their neighborhood for fear of being recognized and stigmatized in their community. Other participants complained about the limited geographic distribution of those services and their low visibility. "If someone didn't have enough contacts and he wanted to feel reassured about himself, he would not know about those services," said one MSM study participant. Thus, utilization of harmreduction services by key populations tends to be low as many KPs are afraid of revealing their risky behavior (Oraby 2013). FSWs and female who inject drugs are said to be particularly hard to reach. According to one key informant, FSWs cannot afford to take time off to go to those centers when they could be seeing customers and making money to feed their families.

"I tell my friends about everything I know from the NGO and I ask them to come with me to learn more. Sometimes I get them the condoms and explain how to use them; I tell my friends who use drugs not to share needles with each other." FSW attending harm-reduction services

"Yes, I feel comfortable now but at the beginning I was very anxious, I felt uncomfortable and refused to let anyone know that I was gay.... However, it is impossible to go for such service in my locality because I don't want anyone to know this information." MSM attending harm-reduction services 


\section{Challenges Facing HIV Prevention Programs in Egypt}

Following are insights shared by our study participants on challenges facing ongoing HIV prevention programs.

\section{Funding}

In-depth interviews with KIs revealed that the HIV response is not well funded in Egypt nor are resources well utilized. According to our study participants, money from the Global Fund, the largest donor for HIV programs in Egypt, goes to the MoHP and mainly covers anti-retroviral drugs (ARV) for people living with HIV. The second-largest donor, USAID, has phased out of funding HIVIAIDS activities since 2006. Our Kls confirmed that funds that are going to programs for young people are meager compared to resources allocated for raising the awareness of the general population. Also, funds supporting HIV prevention activities among KPs are not sufficient to make the desired impact, as stated by KIs. Another KI added that HIV prevention is not high on the government agenda compared to other health issues like hepatitis $C$.

"I think policymakers are committed to the issues of young people but I don't think those commitments have been translated into clear policies that would benefit young people." Official working in an international organization

\section{Conservative social norms}

According to some of our Kls, the public mistakenly believes that people who are involved in HIV prevention activities, especially harm-reduction are doing something against the law or religion. Thus, harm-reduction interventions face a great deal of societal rejection and occasionally negative media publicity as noted by several of our study participants. On several occasions, harm-reduction centers had to suspend their operations as a result of negative media publicity accusing them of promoting vice.

"There was a rumor that I have AIDS
because I am working at this association
and I found that the news spread and I
decided to ignore it in order not to confirm
this rumor." Outreach worker
"Stigma is the greatest challenge and fear
of people who have the disease as if they
have scabies.... This may be a result of a
lack of awareness and what makes it worse
is that some senior medical professors
share the same misconceptions..." MoHP
official

\section{Laws and regulations:}

Some legal barriers may hinder young people's access to SRH services. By Egyptian law, adolescents under the age of 18 cannot receive a medical exam or HIV testing unless parental consent is obtained. ${ }^{15}$ Although Egyptian law does not stipulate marriage as a precondition for receiving reproductive health services, healthcare providers often ask women who are seeking contraception to provide their husband's name and sometimes a copy of his ID. One married adolescent girl mentioned that the healthcare providers at the health unit even asked her husband to be present before offering her a contraceptive

\footnotetext{
${ }^{15}$ Article 18 of Code of Medical Profession.
} 
injection. Moreover, as mentioned above, laws criminalizing some risky behaviors, such as homosexuality, drug use, and sex work, may deter people practicing those behaviors from receiving health services.

In addition, there are no laws and regulations that protect the rights of NGOs or NGO workers who provide harm- reduction services. In fact, condom possession and distribution can be used as evidence of prostitution leading to punishment by law (Setayesh et al. 2014).

"There are restrictions on outreach workers, if they are caught with a condom or a syringe they could be charged of promoting vice." NGO official in Cairo

\section{Youth involvement}

Most participants agreed that youth are not sufficiently involved in programs or policies that affect their health. Some participants attributed low utilization of services to the failure of policymakers and program managers to involve youth and high-risk groups in the design, implementation, and monitoring of programs for people who share many of their characteristics. A few NGOs involve youth in the provision of services (e.g., peer educators or outreach workers), but young people are seldom involved in developing policies or monitoring their implementation.

"Had the government involved us, no one would have opposed them. If they had heard Us, there wouldn't have been drug addicts." 15-year-old female at FGD

"The government doesn't consult with youth on the laws that it enforces on them; they see what they think is right and they do it." FSW in Alexandria

\section{Coordination}

Several participants pointed to the lack of coordination among various ministries and institutions involved in youth programs. Although all those ministries (Ministry of Health and Population, Ministry of Youth, Ministry of Education, Ministry of Higher Education, Ministry of Interior, and Ministry of Defense) deal with young people in one way or another, they do not collaborate on raising youth $\mathrm{SRH}$ awareness. Even within the MoHP, youth SRH issues are not covered in a comprehensive manner due to the vertical nature of programs while NGOs that work with various segments of young people tend to work in isolation from the MoHP. The lack of coordination leads not only to duplication of efforts, but may lead to missing some population subgroups. 


\section{Conclusion and Policy Recommendations}

The present study answered several questions and highlighted a number of issues regarding our understanding of youth vulnerability to HIV. It is true that Egypt's conservative culture has contributed to slowing down the progress of the HIV epidemic, however, traditional norms do not fully protect Egyptian youth from the spread of the HIV infection. Social, economic, cultural, legal, and system factors may contribute to youth engagement in highrisk behaviors and/or deter them from seeking services, thereby increasing young people's HIV vulnerability. The situation is further aggravated by a lack of quantitative data to assess the magnitude of risk behaviors among different subgroups of young people and to thus design appropriate policies and programs to address these behaviors.

Although, they are a minor fraction of the population, key populations' existence must be acknowledged; furthermore, they have links to the general population through marriage or extramarital sexual relations. KPs such as MSM, PWID, and FSWs practice multiple risk behaviors but have limited access to services due to stigma and discrimination. Street children constitute another high-risk group due to their poor living conditions, multiple risk behavior, and limited access to health services. Of the general population, adolescents (age 15-19), young men and women with no education and those in the lowest wealth quintile are particularly vulnerable to HIV infection as a result of their limited knowledge and limited access to information. Widespread stigma and discrimination against people living with HIV and high-risk groups, along with dwindling funds and limited youth involvement in policies and programs that directly affect their lives are formidable barriers that undermine the effectiveness of HIV prevention efforts in Egypt.

To address the above issues, the following recommendations are proposed with the aim of enhancing the effectiveness of HIV prevention programs and curbing the spread of HIV among Egyptian youth. Many of the recommendations below have been voiced by our study participants.

- Mass media should raise public awareness of HIV and its modes of transmission and should rectify misconceptions about the disease and PLHIV. This would help to reduce the stigma associated with HIV and reduce barriers to HIV testing, the entry point to HIV prevention, care and treatment. The movie "Asmaa" which was sponsored by UNAIDS and other agencies is a good starting point that should be capitalized on. ${ }^{16}$

- Parents should be encouraged to discuss SRH topics, including HIV/AIDS, with their adolescent children. Parents need to realize that ignoring the $\mathrm{SRH}$ information needs of young people will not stop them from engaging in risky behavior. Healthcare providers at public and NGO facilities could raise parents' awareness of young people's information needs and provide them with the necessary communication skills.

\footnotetext{
${ }^{16}$ The movie "Asmaa" was produced in 2011 and featured a famous actress who played the role of a wife who contracted HIV from her husband. The movie addresses stigma against WLHIV.
} 
- Information on SRH and HIV prevention should be communicated to various subgroups of young people through various channels (e.g., school curricula, seminars, peer educators, hotlines, internet, and social media). Teachers and peers could be a credible source of information to young people if they are adequately trained. Youth centers and NGO drop-in centers would provide good venues for reaching out-of-school, marginalized young people and those in slum areas. The scope of SRH education should be broadened to encompass sexual and reproductive rights, gender norms, and other socio-cultural factors that negatively impact youth sexual behavior.

- Special attention needs to be paid to empowering young women and addressing cultural norms that discriminate against young women and render them vulnerable to HIV. Adolescent girls, especially those in rural Upper Egypt, are very hard to reach as they are likely to be out of school and their mobility is limited. Programs that provide "safe spaces" to those women such as Ishraq and Meseret Hiwot programs should be scaled up. The Ishraq program offered literacy, sports, and life-skills training to out of school adolescent girls in rural Upper Egypt (Selim et al. 2013) while Meseret Hiwot provided married female adolescents in rural Ethiopia with HIVrelated knowledge, skills and social assets (Erulkar, Lamesgin, and Muthengji 2010).

- SRH services for young people should be integrated within primary healthcare services. Integration would take away some of the stigma associated with SRH services, especially for unmarried youth. Moreover, the premarital exam that is mandated by law should be upgraded to include counseling of prospective couples about SRH and HIV transmission and referral of high-risk individuals to $C T$ services. Primary healthcare providers should receive training in various $\mathrm{SRH}$ issues, including HIV prevention and their negative attitudes toward high risk groups and PLHIV should be addressed.

- Harm-reduction services for high-risk groups should be strengthened and scaled up to additional governorates. Besides providing condoms and sterile needles to key populations, they could provide lubricants, which reduce the risk of HIV transmission among MSM. Moreover, those services should empower key populations with the knowledge and skills to negotiate condom use with their partners, demand their rights to adequate health services, and generate income to support themselves and their families. Special efforts should be made to reach females who inject drugs and FSWs who are the least likely to join harm-reduction programs. Also, public misconceptions about those services should be addressed through mass media and religious institutions. Society needs to understand that tolerance of high-risk groups and providing health service to them does not mean legitimization of high-risk behavior, but is a means of protecting them and other members of society from HIV.

- Policies and laws that have a negative impact on youth SRH should be revisited. Examples include laws mandating HIV testing for applicants to certain jobs, upholding a physician's right to deny health services to some population groups, and restricting punishment to sex workers and not their clients. Moreover, 
laws pertaining to violence against women and girls, early marriage and FGM/C should be adequately enforced. Police officers and attorneys should be offered training in gender-sensitive interpretation of some of the current laws.

- Young people's SRH can be only improved when we better understand the sexual behavior of various groups of young people (including high-risk groups) as well as contextual factors that influence their behavior. As much as qualitative research provides insights into youth $\mathrm{SRH}$ behaviors, more quantitative research is needed to understand the magnitude of those behaviors, their geographic and socioeconomic distribution, and their association with other behaviors or aspects of young people's lives. SYPE and Bio- BSS are good examples of such data which allow policymakers to measure impact of various policies and programs on young people's lives. However, SYPE does not directly investigate young people's sexual behavior, while BBSS is focused on high-risk groups.

- Finally, young people's SRH is an integral component of their overall health and well-being. Effective prevention of HIV can be only achieved when young people are empowered socially, economically, and politically. Broader policy reforms are needed to keep young people in school; provide them with adequate education that builds their knowledge and skills; offer job opportunities that allow young people to make healthy transitions to adulthood, and abolish gender and social disparities that prevent young people from attaining their full potential. 


\section{References}

Abdelbaqy, M. 2013. "An exploratory study of premarital care services in Alexandria." (Unpublished report.) Cairo: Population Council.

Abdel Mawgood, S. 2013. "Self-perception and health seeking behaviors of men who have sex with men in Egypt." (Unpublished report.) Cairo: Population Council.

Abdel-Tawab, N., T. Rabie, Z. Boehmova, L. Hawkins, S. Saher, and A. El Shitany. 2015. "Do public health services in Egypt help young married women exercise their reproductive rights?" International Journal of Gynecology and Obstetrics. 130 Suppl 3: E52-55. http://www.ijgo.org/article/So020-7292(15)00151-4/pdf

Abu-Raddad, L, F.A. Akala, I. Semini, G. Riedner, D. Wilson, and O Tawil. 2010. Characterizing the HIV/AIDS epidemic in the Middle East and North Africa: Time for Strategic Action. Washington, DC: World Bank Publications.

Afawubo, K. and S. Mathey. 2014. "Employment and education effects on HIV/AIDS prevalence rate and economic growth: Empirical investigation in ECOWAS," Applied Economics Letters. 21(11): 755-759.

Assaad, R. and F. Roudi-Fahimi. 2007. Youth in the Middle East and North Africa: Demographic Opportunity or Challenge? Washington, DC: Population Reference Bureau.

Benikrane, M. 2013. "Online information on youth sexual and reproductive health available in Arabic: A content analysis from Egypt." Cairo: Ford Foundation (Unpublished report.)

Betron, M., G. Barker, J.M. Contreras, and D. Peacock. 2012. Men, Masculinities and HIV/AIDS: Strategies for Action. Washington, DC: International Center for Research on Women.

Central Agency for Public Mobilization and Statistics (CAPMAS) (Egypt) and Minnesota Population Center. 2011. "Egypt General Census for Population, Housing, and Establishments 2006." Integrated Public Use. Microdata Series, International: Version 6.1 [Machine-readable database]. Minneapolis: University of Minnesota.

Darwish, M, W. Hamza, M. Aziz|, and A. El-Gazzar. 2013. "Sexual and reproductive health experiences of married adolescent girls in rural Upper Egypt," in Breaking the Silence: Learning about Youth Sexual and Reproductive Health in Egypt. Cairo: Population Council.

DeJong J, B. Shepard, F. Roudi-Fahimi, and L. Ashford. 2007. "Young people's sexual and reproductive health in the Middle East and North Africa," Reproductive Health 14(78): 8.

ElBaradei, M. 2012. "Inequality of opportunity in higher education in Egypt: Indicators and explanations," in A. El Badawy (ed.), Higher Education in Egypt: Does Free Education Lead to 
Equality of Opportunity? Cairo: Population Council, pp. 51-73.

<http://www.popcouncil.org/uploads/pdfs/2012PGY_AccessHigherEdEgypt_ar.pdf>

El-Bassel, N. and S.A. Shaw, A. Dasgupta and S.A. Strathdee. 2014. "Drug use as a driver of HIV risks: Re-emerging and emerging issues," Current Opinion in HIV and AIDS. 9(2): 150-155.

El Damanhoury, H. and D. Abdelhameed. 2013. "Youth-friendly clinics: Exploring Egyptian provider attitudes and communication behaviors about sexual and reproductive health," in Breaking the Silence: Learning about Youth Sexual and Reproductive Health in Egypt. Cairo: Population Council.

El-Kak, F. 2013. "Sexuality and sexual health: Constructs and expressions in the extended Middle East and North Africa," Vaccine. 31: G45-50.

Elsamaloty, E. and F. El-Zanaty. 2010. No to Child Marriage: An Investigative Study on Child Marriage in 6th of October Governorate. Arabic report.

El-Tawila, S. and Z. Khadr. 2004. Patterns of marriage and family formation among youth in Egypt. Cairo: National Population Council.

Erulkar, A., A. Lamesgin, and E.N. Muthengi. 2010. "'Meseret Hiwot' (Base of Life): Supporting Married Adolescents with HIV Prevention and Reproductive Health in rural Ethiopia. Addis Ababa: Population Council.

Family Health International and Ministry of Health Egypt (FHI/MoH). 2010. HIV/AIDS Biological \& Behavioral Surveillance Survey: Round Two Summary Reports. Cairo: $\mathrm{FHI} / \mathrm{MoH}$.

Geel, F. 2013. "Sexual and reproductive health education in Egyptian schools: The ideal and the reality," in N. Abdel-Tawab, S. Saher, and N. El Nawawi (eds.), Breaking the Silence: Learning about Youth Sexual and Reproductive Health in Egypt. Cairo: Population Council.

Ghandour, L.A., F. Mouhanna, R. Yasmine, and F. El Kak. 2014. "Factors associated with alcohol and/or drug use at sexual debut among sexually active university students: Cross-sectional findings from Lebanon," BMC Public Health 14(1): 671.

Hassan, H.M. 2013. "A Survey of father-son communication concerning sexual and reproductive health in Sharkiya, Egypt," in N. Abdel-Tawab, S. Saher, and N. El Nawawi (eds.), Breaking the Silence: Learning about Youth Sexual and Reproductive Health in Egypt. Cairo: Population Council.

Ismail S., N. Abdel-Tawab and L. Sheira. 2015." Marriage and Family Formation Trends among Youth in Egypt" In: Rania Roushdy and Maia Sieverding (eds) Panel Survey of Young People in Egypt (SYPE) 2014. Generating Evidence for policy, programs and research. Cairo: Population Council. 
Jenkins, C.L. and D.A. Robalino. 2003. World Health Organization, Joint United Nations Programme on HIVIAIDS. HIVIAIDS in the Middle East and North Africa: The Costs of Inaction.

Washington, DC: World Bank Publications.

Khattab, H. and M. El Guneidy. 2010. The Agony of AIDS: A Qualitative Study on the Experience of AIDS in Egypt, Cairo: Print House.

Krafft C., 2015. "Educational Experiences of Youth in Egypt: Who attends School, who succeeds, and who struggles". In: Rania Roushdy and Maia Sieverding (eds) Panel Survey of Young People in Egypt (SYPE) 2014. Generating Evidence for policy, programs and research. Cairo: Population Council

Ministry of Health and Population [Egypt], El-Zanaty and Associates [Egypt], and ICF International. 2015a. Egypt Demographic and Health Survey 2014. Cairo and Rockville, MD: Ministry of Health and Population and ICF International.

__. 2015b. Egypt Health Issues Survey 2015. Cairo and Rockville, MD: Ministry of Health and Population and ICF International.

Mossa, M.; D. Mohamed, S. Abd El Samae, et al. 2013. "Causes of underutilization of youth health center in Assiut University: A students' perspective." (Unpublished report). Cairo: Population Council.

Nada, K.H. and A.S. El Daw. 2010. "Violence, abuse, alcohol and drug use, and sexual behaviors in street children of Greater Cairo and Alexandria, Egypt," AIDS 24: S39-44.

National AIDS Program (NAP). 2014. Global AIDS Response Progress Report. Cairo: NAP. 2015. National HIV Programme Situation and Gap Analysis Egypt. Cairo: NAP.

Oraby, D. 2013. "Harm reduction approach in Egypt: The insight of injecting drug users." Harm Reduction Journal. 10(1): 1-5.

Oraby, D. and N. Abdel-Tawab N. 2014. Sexual and Reproductive Health of Women Living with HIV in Egypt: Unmet Needs and Unfulfilled Dreams. Cairo: Population Council.

_.. Forthcoming. Understanding Women's Vulnerability to HIV Infection in Egypt: An Exploratory Study. Cairo: Population Council.

Patel, P, C.B. Borkowf, J.T. Brooks, A. Lasry, A. Lansky, and J. Mermin. 2014. "Estimating per-act HIV transmission risk: A systematic review," AIDS. 28(10): 1509-1519.

Population Council 2007. Reproductive Health and Rights of HIV-Positive Individuals: Establishing a Global Program. New York: Population Council.

Population Council. 2010. The Survey of Young People in Egypt. Cairo: Population Council. 
Population Council and Assiut University. Forthcoming. Married Adolescent Girls in Rural Assiut and Sohag: Limited Choices and Unfulfilled Reproductive Health Needs. Preliminary Report. Cairo: Population Council.

Reed, E., J. Gupta, M. Biradavolu, V. Devireddy, and K.M. Blankenship. 2010. "The context of economic insecurity and its relation to violence and risk factors for HIV among female sex workers in Andhra Pradesh, India," Public Health Reports 125(Suppl 4): 81-89.

Richardson, E.T., S.E. Collins, T. Kung, J.H. Jones, K.H. Tram, V.L. Boggiano, L.G. Bekker, and A.R. Zolopa. 2014. "Gender inequality and HIV transmission: A global analysis," Journal of the International AIDS Society 17:19035 - doi: 10.7448/IAS.17.1.19035.

Roudi-Fahimi, F and S. El-Feki. 2011. Facts of Life. Youth Sexuality and Reproductive Health in the Middle East and North Africa. Washington, DC: Population Reference Bureau

Roushdy, R. and I. Selwaness .2015. ." Young People's Labor Market Outcomes During a Period of Transition " In: Rania Roushdy and Maia Sieverding (eds) Panel Survey of Young People in Egypt (SYPE) 2014. Generating Evidence for policy, programs and research. Cairo: Population Council. "Panel survey of young people in Egypt 2014: Generating evidence for policy, programs, and research." Cairo: Population Council.

Saggurti, N, B. Mahapatra, S. Sabarwal, S. Ghosh, and A. Johri. 2012. "Male out-migration: A factor for the spread of HIV infection among married men and women in rural India," PLOS ONE 7(9): e43222.

Selim, M., N. Abdel-Tawab, K. Elsayed, A. El Badawy, and H. El Kalaawy. 2013. The Ishraq Program for Out-of-School Girls: From Pilot to Scale-Up. Cairo: Population Council.

Setayesh, H., F. Roudi-Fahimi, S. El-Feki, and L. Ashford. 2014. HIV and AIDS in the Middle East and North Africa. Washington, DC: Population Reference Bureau.

Sieverding M. and A. Ragab A., 2015." Marriage and Family Formation Trends among Youth in Egypt" In: Rania Roushdy and Maia Sieverding (eds) Panel Survey of Young People in Egypt (SYPE) 2014. Generating Evidence for policy, programs and research. Cairo: Population Council.

Soliman, C., S. Elkamhawi, S. Hassounah, and O. Abaza. 2009. Meeting Adolescent Reproductive Health Needs in Egypt: Final Report. New York: FHI 360.

Tag-Eldin, M.A., M.A. Gadallah, M.N. Al-Tayeb, M. Abdel-Aty, E. Mansour, M. Sallem. 2008. "Prevalence of female genital cutting among Egyptian girls," Bulletin of the World Health Organization. 86(4): 269-274.

United Nations Children's Fund (UNICEF). n.d. Street Children: Issues and Impact. Available at: http://www.unicef.org/egypt/protection 4397.html. Accessed December 2015 
_. 2011. Opportunity in Crisis: Preventing HIV from Early Adolescence to Young Adulthood. New York: UNICEF.

2013. Towards an AIDS-Free Generation - Children and AIDS: Sixth Stocktaking Report. New York: UNICEF.

United Nations Development Programme (UNDP). 2014. Human Development Report 2014 Sustaining Human Progress: Reducing Vulnerabilities and Building Resilience. New York: UNDP.

United Nations High Commissioner Refugees (UNHCR). 2014. Woman Alone: The Fight for Survival by Syria' Refugee Women. New York: UNHCR.

United Nations Joint Program on HIVIAIDS (UNAIDS). 2015. Fact Sheet 2015. New York: UNAIDS.

__. 2014. "AIDSinfo" http://aidsinfo.unaids.org/\#. 2014.

__. 2013. Global Report: UNAIDS Report on the Global AIDS Epidemic 2013. New York: UNAIDS.

__. 2012. Standing Up, Speaking Out: Women and HIV in the Middle East and North Africa. New York: UNAIDS.

Wahba, J. 2015. "Through the keyhole: International migration in Egypt," in R. Assaad and C. Krafft (eds.), The Egyptian Labor Market in an Era of Revolution. Oxford: Oxford University Press, pp. 198-217.

Yousri, Y. and M.H. Mamdouh. 2013. "Mother-daughter communication about sexual and reproductive health in Alexandria, Egypt," in Breaking the Silence: Learning about Youth Sexual and Reproductive Health in Egypt. Cairo: Population Council. 
